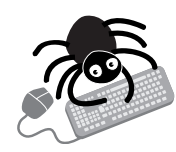

Please visit the Heart website (www.heartinl.com) for links to these articles many to full text.
(Crl) 0.72 to 1.11 ) or the need for coronary artery bypass surgery (CABG) (OR 1.01, 95\% Crl 0.79 to 1.31 ). Coronary stenting did reduce the rate of restenosis (OR $0.52,95 \% \mathrm{Crl} 0.37$ to 0.69 ) and the need for repeated $\mathrm{PCl}(\mathrm{OR} 0.59,95 \% \mathrm{Crl} 0.50$ to 0.68$)$. Dramatically reduced restenosis rates with the use of drug eluting stents may, however, produce further benefits that still need to be assessed.

A Brophy JM, Belisle P, Joseph L. Evidence for use of coronary stents: a hierarchical Bayesian meta-analysis. Ann Intern Med 2003;138:777-86.

\section{Ischaemic heart disease}

Angiographically complex plaques have more inflammation - Previous work has shown that complex plaques are found in acute coronary syndromes (ACS) more often than in stable angina, and that inflammation plays a role in ACS. This study links the two findings. A total of 79 patients with unstable $(n=46)$ or stable angina $(n=33)$ underwent directional coronary atherectomy for culprit lesions. The mean (SD) percentage of macrophages in atherectomy specimens from patients with unstable angina was greater than in specimens from patients with stable angina $(21(14) \%$ v $13(10) \%, p=0.01)$; similar results were seen when complex coronary lesions were compared with simple lesions (23 (13)\% v 9 (8)\%, p < 0.001).

$\Delta$ Meuwissen $M$, van der Wal AC, Koch KT, van der Loos CM, Chamuleau SAJ, Teeling P, de Winter RJ, Tijssen JGP, Becker AE, Piek JJ. Association between complex coronary artery stenosis and unstable angina and the extent of plaque inflammation. Am J Med 2003;114:521-7.

Exercise for pleasure is better than exercise at work $>$ Does having a strenuous job provide any protection from cardiovascular risk? Leisure activity showed a clear inverse association with risk of coronary heart disease (CHD). A case-control study of 312 patients with known coronary artery disease (CAD) and 479 controls was performed. Compared with subjects who reported no summer leisure activities, the odds ratio for CHD was $0.85195 \%$ confidence interval (CI) 0.47 to 1.53 ) in the category < 1 hour/ week; $0.60(95 \% \mathrm{Cl} 0.38$ to 0.95$)$ in the category $1-2$ hours/week; and $0.39(95 \% \mathrm{Cl} 0.26$ to 0.59$)$ in the category > 2 hours/week, after full adjustment for covariates. Similar results were obtained for winter activities. By contrast, there was a strong positive association between work related activity and risk of $\mathrm{CHD}$. Furthermore, levels of inflammatory markers such as $C$ reactive protein, serum amyloid A, interleukin 6 , and intercellular adhesion molecule 1 were inversely and independently associated with leisure time activities, but not with work.

\ Rothenbacher D, Hoffmeister A, Brenner H, Koenig W. Physical activity, coronary heart disease, and inflammatory response. Arch Intern Med $2003 ; 163: 1200-5$.

Women are most at risk of ACS during and after menses - ACS in pre-menopausal women is rare, but not unknown. In 27 women collected over four years, all the women had at least one known risk factor for coronary artery disease; the most common was a family history of cardiovascular disease. The mean (SD) age of the 27 women was 43 (4) years (range 33-51 years). All of the acute coronary events $(n=27)$ occurred within the first half of the menstrual cycle ( $p<0.00001$ compared with no events during the second half of the menstrual cycle). Significantly more women (19 v 8 women) had their acute coronary event within six days after the onset of menstruation than later during the menstrual cycle $(p<0.0001)$. Fluctuating hormone values are probably playing a role.

A Hamelin BA, Méthot J, Arsenault M, Pilote S, Poirier P, Plante S, Bogaty P. Influence of the menstrual cycle on the timing of acute coronary events in premenopausal women. Am J Med 2003;1 14:599-602.

Routine use of stents does not reduce death/MI/CABG rates - A total of 29 trials involving 9918 patients were identified. A meta-analysis did not provide evidence for a difference between routine coronary stenting and standard percutaneous coronary intervention (PCI) in terms of deaths or myocardial infarction (MI) lodds ratio (OR) 0.90, 95\% credible interval

\section{Hypertension}

Hypertension in pregnancy carries a long term risk $\rightarrow$ Vital statistics collected in England and Wales between 1938 and 1960 suggest that pregnancy has an effect as parous women have a higher mortality from hypertension, ischaemic and degenerative heart disease, and cerebrovascular disease than nulliparous women. In the present study from Scotland, there were significant positive associations between pre-eclampsia/ eclampsia or gestational hypertension and later hypertension. The adjusted relative risks varied from 1.13-3.72 for gestational hypertension and 1.40-3.98 for pre-eclampsia or eclampsia. The adjusted incident rate ratio for death from stroke for the pre-eclampsia/eclampsia group was $3.59(95 \% \mathrm{Cl} 1.04$ to 12.4). There was no increase in the risk of death from coronary disease, however.

\ Wilson BJ, Watson MS, Prescott GJ, Sunderland S, Campbell DM, Hannaford P, Smith WCS. Hypertensive diseases of pregnancy and risk of hypertension and stroke in later life: results from cohort study. BM 2003;326:845.

Diet and lifestyle modification may avoid pharmacotherapy in mild hypertension $-\ln 810$ adults with above optimal blood pressure $(120-159 \mathrm{~mm} \mathrm{Hg}$ systolic and 80-95 mm Hg diastolic) not taking antihypertensive medications, three intervention groups were assessed: (1) "established", a behavioural intervention that implemented established recommendations ( $\mathrm{n}=268$ ); (2) "established plus DASH", which also implemented the DASH diet, which is high in fruit and fibre and low in saturated fat ( $n=269)$; and (3) an "advice only" comparison group $(n=273)$. Both behavioural interventions significantly reduced weight, improved fitness, and lowered sodium intake. The established plus DASH intervention also increased fruit, vegetable, and dairy intake. After subtracting change in advice only, the mean net reduction in systolic blood pressure was $3.7 \mathrm{~mm} \mathrm{Hg}$ $(p<0.001)$ in the established group and $4.3 \mathrm{~mm} \mathrm{Hg}(\mathrm{p}<0.001)$ in the established plus DASH group; the systolic blood pressure difference between the established and established plus DASH groups was $0.6 \mathrm{~mm} \mathrm{Hg}(p=0.43)$. At baseline, hypertension prevalence was $38 \%$; at six months prevalence was $26 \%$ in the advice only group, $17 \%$ in the established group $(p=0.01 \mathrm{com}-$ pared with the advice only group), and $12 \%$ in the established plus DASH group ( $p<0.001$ compared with the advice only group; $p=0.12$ compared with the established group).

$\Delta$ Writing Group of the PREMIER Collaborative Research Group. Effects of comprehensive lifestyle modification on blood pressure control: main results of the PREMIER clinical trial. JAMA 2003;289:2083-93.

\section{General cardiology}

Predicting diabetes mellitus with more than glucose and HbA $_{1 \mathrm{c}}$ In a nested case-control study from the Women's Health Study, 126 women with diabetes diagnosed during a four year follow up period were compared with 225 age matched controls. Fasting insulin concentration and proinsulin:insulin ratio were assessed in quartiles, and proinsulin level was assessed in categories ( $\leqslant 4.0 \mathrm{pmol} / \mathrm{l}, 4.01-6.99 \mathrm{pmol} / \mathrm{l}, \geqslant 7.0 \mathrm{pmol} / \mathrm{l})$. The risk of 
developing type 2 diabetes was determined using conditional logistic regression analysis that adjusted for body mass index and other diabetes risk factors. Women with elevated insulin values in the highest as compared with the lowest quartile were more likely to develop diabetes (OR 5.6, 95\% Cl 1.8 to 17.6 ), as were women with elevated ( $\geqslant 7.0 \mathrm{pmol} / \mathrm{I} v \leqslant 4.0 \mathrm{pmol} / \mathrm{l})$ proinsulin values (OR $16.4,95 \% \mathrm{Cl} 5.8$ to 46.8 ) and women with proinsulin: insulin ratios in the highest quartile (OR 9.6, 95\% $\mathrm{Cl} 3.1$ to 30.8 ). Similar results were observed among women with a baseline haemoglobin $A_{1 c}$ concentration $\leqslant 6.0 \%$.

$\Delta$ Pradhan AD, Manson JE, Meigs JB, Rifai N, Buring JE, Liu S, Ridker PM Insulin, proinsulin, proinsulin:insulin ratio, and the risk of developing type 2 diabetes mellitus in women. Am J Med 2003;114:438-44.

AICD therapy summarised by meta-analysis - Compared with usual care (most commonly amiodarone treatment), use of implantable cardioverter-defibrillators (ICDs) in eight trials significantly reduced sudden cardiac death (relative risk (RR) 0.43, 95\% $\mathrm{Cl} 0.35$ to 0.53 ) and all cause mortality (RR $0.74,95 \% \mathrm{Cl} 0.67$ to 0.82 ). The included trials were divided a priori into two categories: secondary prevention (involving patients resuscitated after cardiac arrest or unstable ventricular tachycardia or ventricular fibrillation, $\mathrm{n}=1963$ ) and primary prevention (involving patients at increased risk for sudden cardiac death but without documented cardiac arrest, ventricular fibrillation, or ventricular tachycardia, $n=2946$ ). Regardless of baseline risk, ICDs were equally efficacious in preventing sudden cardiac death in both types of trials (RR 0.50 (95\% $\mathrm{Cl} 0.38$ to 0.66 ) for secondary prevention $v$ RR 0.37 ( $95 \% \mathrm{Cl} 0.27$ to 0.50 ) for primary prevention).

$\Delta$ Ezekowitz JA, Armstrong PW, McAlister FA. Implantable cardioverter defibrillators in primary and secondary prevention: a systematic review of randomized, controlled trials. Ann Intern Med 2003;138:445-52.

Biventricular AICDs improve quality of life but not survival - Of 369 randomised patients who received devices with combined biventricular resynchronisation (CRT) and ICD capabilities, 182 were controls (ICD activated, CRT off) and 187 were in the CRT group (ICD activated, CRT on). At six months, patients assigned to CRT had a greater improvement in median $(95 \% \mathrm{Cl})$ quality of life score $(-17.5(95 \% \mathrm{Cl}-21$ to -14$) v-11.0(95 \% \mathrm{Cl}$ -16 to -7$), \mathrm{p}=0.02)$ and functional class $(-1)(95 \% \mathrm{Cl}-1$ to -1$)$ $v 0(95 \% \mathrm{Cl}-1$ to 0$), p=0.007)$ than controls, but were no different in the change in distance walked in six minutes. Peak oxygen consumption increased by $1.1 \mathrm{ml} / \mathrm{kg} / \mathrm{min} 195 \% \mathrm{Cl} 0.7$ to $1.6 \mathrm{ml} / \mathrm{kg} / \mathrm{min})$ in the CRT group versus $0.1 \mathrm{ml} / \mathrm{kg} / \mathrm{min}(95 \% \mathrm{Cl}$ -0.1 to $0.8 \mathrm{ml} / \mathrm{kg} / \mathrm{min}$ ) in controls ( $p=0.04)$, although treadmill exercise duration increased by 56 seconds $195 \% \mathrm{Cl} 30$ to 79 seconds) in the CRT group and decreased by 11 seconds $195 \% \mathrm{Cl}$ -55 to 12 seconds) in controls ( $p<0.001$ ). No significant differences were observed in changes in left ventricular size or function, overall heart failure status, survival, and rates of hospitalisation.

$\Delta$ Young JB, Abraham WT, Smith AL, Leon AR, Lieberman R, Wilkoff B, Canby RC, Schroeder JS, Liem LB, Hall S, Wheelan K. Combined cardiac resynchronization and implantable cardioversion defibrillation in advanced chronic heart failure: the MIRACLE ICD trial. JAMA 2003;289:2685-94.

Pacemaker therapy is no good for vasovagal syncope $>$ Of the 52 patients randomised to ODO (pacemaker off), 22 (42\%) had recurrent syncope within six months compared with $16(33 \%)$ of 48 patients in the DDD (pacemaker on) group. The cumulative risk of syncope at six months was $40 \%(95 \% \mathrm{Cl} 25 \%$ to $52 \%)$ for the ODO group and $31 \%(95 \% \mathrm{Cl} 17 \%$ to $43 \%)$ for the DDD group. The relative risk reduction in time to syncope with DDD pacing was $30 \%(95 \% \mathrm{Cl}-33 \%$ to $63 \%$; one sided $p=0.14)$. Lead dislodgement or repositioning occurred in seven patients. One patient had vein thrombosis, another had pericardial tamponade leading to removal of the pacemaker system, and a third had infection involving the pacemaker generator. What is not clear is how many patients truly had bradycardia rather than vasodilatation induced syncope, for which pacing would not be appropriate. Caution is required in view of the small size of the group.

A Connolly SJ, Sheldon R, Thorpe KE, Roberts RS, Ellenbogen KA, Wilkoff BL, Morillo C, Gent M, for the VPS II Investigators. Pacemaker therapy for prevention of syncope in patients with recurrent severe vasovagal syncope: second vasovagal pacemaker study (VPS II): a randomized trial. JAMA 2003;289:2224-9.
Age alone may not be important when deciding on warfarin treatment for $\mathbf{A F}>\mathrm{A}$ history of cerebrovascular accident (CVA), hypertension, symptomatic CAD, and diabetes were used to identify a higher risk population for stroke in the presence of atrial fibrillation (AF). Using data from six trials of aspirin in $A F$, with 2501 patients, the risk of CVA in the absence of these factors was 1.1 per 100 patient years (PY), equivalent to that of the general population. This compares to the overall group rate of $3.5 \mathrm{per}$ 100 PY. Even in the over 75 years group, $16 \%$ fitted this low risk category. Warfarin treatment in the low risk group resulted in a CVA rate of 1.5 per $100 \mathrm{PY}$ ( $p=N S v$ aspirin).

$\triangle$ van Walraven C, Hart RG, Wells GA, Petersen P, Koudstaal PJ, Gullov AL, Hellemons BSP, Koefed BG, Laupacis A. A clinical prediction rule to identify patients with atrial fibrillation and a low risk for stroke while taking aspirin. Arch Intern Med 2003;163:936-43.

Low level raised troponin predicts bad outcome in systemic amyloidosis - Patients with primary systemic amyloidosis that affects the heart have a poor outlook. Cardiac troponins T and I (cTnT, cTnl) are highly specific and sensitive biomarkers of myocardial injury. In 261 patients newly diagnosed as having primary systemic amyloidosis, median survival for patients with detectable cTnT and cTnl (six and eight months, respectively) was worse than that for those with undetectable values $(22$ and 21 months, respectively). Median and 25th and 75th percentile values for cTnT were $0.024 \mu \mathrm{g} / \mathrm{l},<0.01 \mathrm{\mu g} / \mathrm{l}$, and $0.084 \mathrm{\mu g} / \mathrm{l}$, and for cTnl were $0.1 \mathrm{\mu g} / \mathrm{l}, 0.05 \mathrm{\mu g} / \mathrm{l}$, and $0.24 \mathrm{\mu g} / \mathrm{l}$, respectively. After multivariate analysis, cTnT proved a better predictor of survival than CTnl.

$\Delta$ Dispenzieri A, Kyle RA, Gertz MA, Therneau TM, Miller WL, Chandrasekaran K, McConnell JP, Burritt MF, Jaffe AS. Survival in patients with primary systemic amyloidosis and raised serum cardiac troponins. Lancet 2003:361:1787-9.

\section{Basic science}

Growing new blood vessels - The establishment of stable and functional blood vessel networks is a complex process that requires several angiogenic factors to stimulate vessel sprouting and remodelling of the primitive vascular network. Clinical delivery of either vascular endothelial growth factor (VEGF) or fibroblast growth factor (FGF-2) alone has produced some controversial results in the treatment of cardiac ischaemia. FGF-2 and VEGF are potent angiogenic factors in vivo and platelet derived growth factor (PDGF-BB) has a substantial role in the stabilisation of newly formed blood vessels. This paper describes the use of FGF-2 and VEGF alone or in combination with PDGF-BB. The authors discovered in initial studies in mouse cornea that single angiogenic factors were unable to establish stable vascular networks. In contrast, a combination of PDGF-BB and FGF-2, but not PDGF-BB and VEGF or VEGF and FGF-2, synergistically induced angiogenesis and long lasting functional vessels. Subsequently, in both rat and rabbit ischaemic hind limb models, PDGF-BB and FGF-2 together notably stimulated collateral arteriogenesis after ligation of the femoral artery, and induced the formation of vascular networks that remained stable for more than a year, even after depletion of angiogenic factors.

$\Delta$ Cao R, Bråkenhielm E, Pawliuk R, Wariaro D, Post W, Wahlberg E, Leboulch $P, C a o$ Y. Angiogenic synergism, vascular stability and improvement of hind-limb ischemia by a combination of PDGF-BB and FGF-2. Nature Med 2003;9:604-13

\section{Journals scanned}

American Journal of Medicine; American Journal of Physiology: Heart and Circulatory Physiology; Annals of Emergency Medicine; Annals of Thoracic Surgery; Archives of Internal Medicine; BM; Chest; European Journal of Cardiothoracic Surgery; Lancet; JAMA; Journal of Clinical Investigation; Journal of Diabetes and its Complications; Journal of Immunology; Journal of Thoracic and Cardiovascular Surgery; Nature Medicine; New England Journal of Medicine; Pharmacoeconomics; Thorax

\section{Reviewers}

Dr Diana Gorog, Dr Akhil Kapur, Dr Masood Khan, Dr Pipin Ko, Dr Vias Markides, Dr Oliver Segal, Dr Andrew Sharp, Dr Tom Wong 